Oral Section

\title{
Droplet evaporation patterns of wheat seed leakages differ following treatments with arsenic at ultra-high dilution level
}

\author{
Maria Olga Kokornaczyk ${ }^{1}$, Francesco Borghini ${ }^{2}$, Giovanni Dinelli, \\ Ilaria Marotti ${ }^{1}$, Grazia Trebbi ${ }^{1}$, Lucietta Betti $^{1}$
}

1Department of Agroenvironmental Sciences and Technologies, University of Bologna, Italy

2Department of Medical Therapy, University of Chieti, Chieti, Italy

\begin{abstract}
Introduction: "Agro-homeopathy" plays an important role in sustainable agriculture providing cost-saving and residue-free plant treatments for the improvement of yield and the management of diseases and pests [1]. However, one of the main difficulties in "agro-homeopathy" is the exact choice of the right remedy and dilution, which requires the performance of many time-consuming trials.

The droplet evaporation method could constitute a screening method for evaluating the efficacy of extremely low doses and high dilutions on plants. Droplet patterns prepared out of wheat seed leakages show differences in their complexity in relation to the seed vigour [2]. Here we show that this structure-forming capacity of seed leakages prepared in water or in ultra-high diluted (UHD) solutions may give a reliable picture of the treatment's stimulating or inhibiting influence on plant vitality.
\end{abstract}

Materials and Methods: Part of the seeds was stressed with $0.1 \% \mathrm{As}_{2} \mathrm{O}_{3}$ (As) aqueous solution [3]. The droplet patterns were prepared out of four samples: non-stressed (ns) seeds in water, ns-seeds in As 45x, stressed (s) seeds in water, s-seeds in As 45x. The experiment was performed in a 3 day repetition, 3 replicates per day, and 5 droplets per each replicate. The resulting patterns were evaluated by means of the ImageJ software [4] for their local connected fractal dimension (LCFD) values. The plant vigour of the four samples was evaluated by means of in vitro wheat growth $[5,6]$.

Results: The mean LCFD of patterns deriving from s-seeds was significantly lower (1.4, standard error (SE) $0.04)$ vs. ns-seeds (1.7, SE 0.02). Moreover, for both ns- and s-seeds, the LCFD was significantly higher with treatment As 45x vs. water (1.8, SE 0.05 vs. 1.7, SE 0.03 for ns-seeds, and 1.5, SE 0.04 vs. 1.2, SE 0.05 for sseeds). The results of the growth test showed a significant vigour decrease caused by As stress (shoot length $19.7 \mathrm{~mm}$, SE 1.2) vs. ns-seeds (22.4mm, SE 1.5); a significant stimulating effect following As $45 \mathrm{x}$ treatment was observed for both s-seeds (25.1mm, SE 1.1) and ns-seeds (31.4 mm, SE 1.3). Significant differences are at $\mathrm{P}<0.05$.

Discussion: The droplet patterns seem to be a sensitive tool for visualizing the effectiveness of UHD on seeds. The experiment showed that the pattern complexity increased with the application of the treatment for both ns- and s-seeds. The growth test provided a further verification of these results. 
Conclusions: Further confirmations are required, but even as it is now the droplet evaporation method may be considered a promising tool for "agro-homeopathic" screening tests.

Keywords: Droplet evaporation, patterns, wheat seeds, arsenic trioxide, ultra high dilutions.

\section{References:}

[1] Betti L, Trebbi G, Majewsky V, Scherr C, Shah-Rossi D, Jaeger T, Baumgartner S. Use of homeopathic preparations in phytopathological models and in field trials: a critical review. Homeopathy 2009; 98: 244-266.

[2] Kokornaczyk MO, Dinelli G, Marotti I, Benedettelli S, Nani D, Betti L. Self-organized crystallization patterns from evaporating droplets of Common wheat grain leakages as a potential tool for quality analysis. TheScientificWorldJ. 2011; 11: 1712-1725.

[3] Brizzi M, Elia V, Trebbi G, Nani D, Peruzzi M, Betti L. The efficacy of ultra molecular aqueous dilutions on a wheat germination model as a function of heat and aging-time. e-CAM 2011; Article ID 696298: 11p. doi: 10.1093/ecam/nep217.

[4] Collins TJ. ImmageJ for microscopy. BioTechniques. 2007; 43: 25-30.

[5] Betti L, Brizzi M, Nani D, Peruzzi M. Effect of high dilutions of Arsenicum album on wheat seedlings from seed poisoned with the same substance. Br. Homeopath. J. 1997; 86: 86-89.

[6] Brizzi M, Lazzarato L, Nani D, Borghini F, Peruzzi M, Betti L. A biostatistical insight into the $\mathrm{As}_{2} \mathrm{O}_{3}$ high dilution effects on the rate and variability of wheat seedling growth. Forsch. Komplementmed. 2005; 12 : 277 283.

\section{(c)) EY-Nc-ND Licensed to GIRI}

Support: authors declare that this study received no funding

Conflict of interest: authors declare there is no conflict of interest

Received: 01 June 2012; Revised: 10 August 2012; Published: 30 September 2012.

Correspondence author: Maria Olga Kokornaczyk, maria.kokornaczyk@unibo.it, http://www.dista.unibo.it

How to cite this article: Kokornaczyk MO, Borghini F, Dinelli G, Marotti I, Trebbi G, Betti L. Droplet evaporation patterns of wheat seed leakages differ following treatments with arsenic at ultra-high dilution level. Int J High Dilution Res [online]. 2012 [cited YYYY Month dd]; 11(40):115-116. Proceedings of the XXVI GIRI Symposium; 2012 Sep 20-22; Florence (Italy). GIRI; 2012; Available from: http://www.feg.unesp.br/ ojs/index.php/ijhdr/article/view/564/595 